\title{
Environmental Performance and Sustainable Development
}

\author{
Razeeya Jaffeer (Corresponding author) \\ Jozef Stefan International Postgraduate School \\ Jamova 39, Ljubljana 1000, Slovenia \\ Tel: 94-7781-73524 E-mail: razee9@yahoo.com
}

$\begin{array}{ll}\text { Received: September 7, } 2011 & \text { Accepted: October 13, } 2011 \quad \text { Published: December 1, } 2011 \\ \text { doi:10.5539/jsd.v4n6p181 } & \text { URL: http://dx.doi.org/10.5539/jsd.v4n6p181 }\end{array}$

\begin{abstract}
This paper presents an overview of environmental indexes and indicators. A short definition of some indicators is considered and a new environmental performance framework is proposed in close relation to environmental performance index (EPI). The aim is to explore the relation between indicators and as well as to find the most suited index that could gear environmental aspects towards SD. New Environmental Performance scores (i.e. new aggregate scores (NAS) according to the proposed framework) of some selected countries were used for comparison purpose and the poor performance in some policy categories was analyzed in a time series data contextually. Sri Lanka is considered as a case study. The result of the analysis shows that Sri Lanka's performance in air pollution category and environmental burden on diseases are poor. To conclude, the environmental performance category analysis shows that the growing demand on scarce resources and pollution play an important role in environmental stress. The use of fossil fuel is the major contributor to $\mathrm{CO}_{2}$ emission in Sri Lanka. The increasing trend of $\mathrm{CO}_{2}$ emission contributes to the environmental burden of diseases and air pollution in Sri Lanka.
\end{abstract}

Keywords: Environmental performance, Sustainable development, Index, $\mathrm{CO}_{2}$, Environmental burden

\section{Introduction}

\subsection{Overview of indexes and indicators}

Indicators express a wider image than the underlying statistics imply. The strength and weakness of indicators based on their selection and it helps in decision making process and data manipulation (United Nations, 2001). Aggregation of statistics and indicators are formed into compound indices with or without weighted averages and mathematical reduction of correlated Indicators. The indicators show different dimensions of SD such as economic, environmental, social and institutional. Indices reflect overall concepts or social goals or socioeconomic welfare or environmental or ecological sustainability. Green Accounting Systems and indicator framework such as Pressure-State-Response (PSR), Driver-Pressure-State-Response (DPSR), and Driver-State-Pressure-Impact-Response (DSPIR) is used for compilation of environmental indicators. Index of sustainable economic welfare (ISEW) is based on final consumption and related to national accounts and later modified to accommodate welfare effects which are not measured by Gross domestic product (GDP) and private consumption, this later renamed as genuine progress index (GPI) (Jonathan et al., 2008). Happy Planet Index (HPI) measures real economic well-being (NEF, 2010). Non monetary indicators such as human development index (HDI) do not include environmental concerns whereas environmental sustainability index (ESI), sustainable development index (SDI), and welfare index (WI) cover environmental issues. ESI later environmental performance index (EPI) covers environmental pressure and quality that are capable of dealing with environmental concerns of a country. Indicators support policy formulation and evaluation. Policy requires targets or benchmark against progress or failure to be assessed. Composite indices demonstrate caution for urgent actions and information in a concise manner and preferred by policy makers. Broadly speaking both indicators and indices are not explicit in their goals and the selected indicators express the core goals. SD has no uniform consensus on metrics, indices or frameworks (Sikdar, S. K., 2007). The problem has given rise to a number of indicators, metrics and tools (Wilson et al, 2007). Although in the 70's indicators for SD was discussed, the Brundtland Report of 1987, on 'our common future' made a prominent promise to SD but, it has taken a decade to implement until the 'World Summit' on SD in 2002, Johannesburg, South Africa. A set of SD indicators developed by UN Conference on SD in 1992 that tested by countries have proposed that the indicators and methodologies were not good enough for national needs (Eurostat, 1997). The indicators legitimize the results for 
more consultation rather than based on conceptual framework. Therefore, indicators communicate the policy issues very successfully but not the SD as desired. The complexity behind the SD makes it more difficult to measure directly unless it includes common monitory indicators that can be meaningfully valued using existing data.

Education and life expectancy are good indicators for human capital as they help to develop human aspect of life values. Usually, economic indicators measure investment and depreciation, natural indicators measure depletion and degradation, and stable climate as a natural capital use emission of greenhouse gases as an indicator. Some mostly use policy indicators in SD based on environment, economic and social groupings. Some national and international public policy level indicators were developed as a result of no uniform consensus on indices and framework, for example: happy planet index (HPI); human development index (HDI) measures life expectancy, education and national production; environmental sustainability index (ESI) stress on preserving environmental resources; and environmental performance index (EPI) measures environmental stress.

\subsection{Selection of countries}

El Salvador, Senegal, Sri Lanka, Vietnam, Thailand and Philippines are the countries selected for comparison purpose only. All the selected countries are in the band of Lower Middle Income economies (World Bank, 2010) located in the tropic of cancer, having tropical climate, and elevation extremes ranges 0 to $3000 \mathrm{~m}$ above sea level and rolling plains of terrain. According to World Bank list of economies as on December 2010, El Salvador, Senegal, Sri Lanka, Vietnam, Thailand and Philippines are grouped under Lower Middle Income economies band \$ 996 to \$3945, based on 2009 GNI per capita using WB Atlas Method of calculation and effective till July 2011 (World Bank, 2010).

\section{Experiment}

\subsection{Evaluation of some indexes}

Human development index (HDI)

HDI (UNDP, 2010) is a summary of composite index that measures a country's average achievements in three basic aspects of human development: longevity, knowledge, and a decent standard of living. Each index is calculated as follows:

$X_{\text {index }}=\left(V_{\text {actual }}-V_{\min }\right) /\left(V_{\max }-V_{\min }\right) ;$ Where: $X=\{$ Health, Education, Income $\}$

$H D I=(\text { Health index } * \text { Education Index } * \text { Income Index })^{1 / 3}$; where $0<H D I<1$

Happy planet index (HPI)

HPI (Herman Daly, 2009) capture achieving sustainable wellbeing through ecological efficiency. Life expectancy, life satisfaction and ecological footprint (EF) are components of HPI.

$H P I=[$ happy life years $/(E F+\alpha)] * \beta ; \quad$ where $\alpha=3.35$ and $\beta=6.42$

Environmental performance index (EPI)

25 Indicators $\rightarrow 10$ Policy Categories $\rightarrow 2$ Objectives $\rightarrow 2010$ EPI (Environmental performance Index, Report, 2010) scores

First, the scores calculated for each ten categories based on one to four indicators. Second, the scores calculated for the Objectives with allocated weights. Third, the overall EPI calculated based on the mean of the two objective scores. Then the ranking is based on index scores.

\subsection{Proposed framework for environmental performance}

25 indicators (same as EPI indicators) $\rightarrow 6$ Policy Categories $\rightarrow 3$ Objectives $\rightarrow$ environmental performance New Score

\section{Calculation of new aggregate scores}

The new aggregate scores were calculated according to the proposed framework as.

Calculation of water pollution effect on human and ecosystem

$$
W P_{H E}=\left(W_{H}+W_{E}\right) * \alpha ;
$$

Where $\mathrm{W}_{\mathrm{H}}=$ Water effect on human; $\mathrm{W}_{\mathrm{E}}=$ Water effect on ecosystem; $\alpha=0.494 ; \mathrm{WP}_{\mathrm{HE}}=$ Water pollution effect on human and ecosystem

Calculation of air pollution effect on human and ecosystem 


$$
A P_{H E}=\left(A_{H}+A_{E}\right) * \alpha ;
$$

Where $\mathrm{AP}_{\mathrm{HE}}=$ Air pollution effect on human and ecosystem; $\mathrm{A}_{\mathrm{H}}=$ Air pollution effect on human; $\mathrm{A}_{\mathrm{E}}=\mathrm{Air}$ pollution effect on ecosystem; $\alpha=0.494$

Calculation of ecosystem vitality

$$
E V=\left(E_{F r}+E_{F}+E_{a}\right) * \alpha ;
$$

Where $\mathrm{EV}=$ Ecosystem Vitality $E_{F r}=$ Ecosystem forestry $\mathrm{E}_{\mathrm{F}}=$ Ecosystem fisheries $; \mathrm{E}_{\mathrm{a}}=$ Ecosystem agriculture; $\alpha$ $=0.330$

Calculation of biodiversity

$$
B_{n}=B * \alpha
$$

Where $\mathrm{B}_{\mathrm{n}}=$ Biodiversity new score; $\mathrm{B}=$ Biodiversity; $\alpha=1.07$;

Calculation of Climate change and environmental burden of disease

The climate change and environmental burden of disease is calculated and weighted same as the EPI.

\section{Results and discussion}

\subsection{New environmental performance scores for selected countries}

Air pollution includes effects on human and ecosystem. Water pollution includes effects on human and ecosystem. The air pollution and water pollution forms the objective of health-eco vitality of our proposed framework. Among countries: Sri Lanka has the best performance in climate change category and worst performance in air pollution category. Senegal performed worst in environmental burden of disease while Vietnam was best in that category. Almost all countries performed well in ecosystem vitality and water pollution (Refer Table 1). Thailand leads in water pollution control, biodiversity and ecosystem vitality sectors. Except Senegal all most all other countries have done better in water pollution category. This is due to the difficulty in access to water sanitation and accesses to drinking water in Senegal (Environmental performance Index, Report, 2010). Compared to the other countries El Salvador has not performed very well in protecting the biodiversity (Table 1). This is due to not enough protected area (Environmental performance Index, Report, 2010). In El Salvador the proportion of land covered by forest is only 14.4\% compared to Sri Lanka 29.9\%; Thailand 28.4\%; Senegal 45\%; Philippines 24\%; Vietnam 39.7\% (Data World Bank, 2005). Vietnam's biodiversity score was lower than average, this may be due to higher economic development process, currently Vietnam's GDP real growth rate annual \% adjusted for inflation is $6.8 \%$ compared to Sri Lanka 6.9\%; Thailand 7.6\%; Senegal 3.9\%; Philippines 7.3\%; Salvador 1.2 \% (CIA fact files, 2005). Senegal and Sri Lanka performance on the environmental burden of disease were below the group average (Table 1). Thailand, Vietnam and Senegal scored lower than average in Climate change control measures and in conserving ecosystem (Table 1). It is also clear that the growing demand on scarce resources and the pollution plays an important role in environmental stress (Table 1).

Comparing the New Aggregate Ranking with EPI ranking:

Senegal, Sri Lanka, Vietnam and Philippines have no change in ranking position while Salvador had moved negative three positions from EPI (Table 2). Thailand moved three positions positive from EPI (Table 2). The reason for these position changes is that Thailand scored top performance in ecosystem vitality, water pollution and biodiversity categories and El Salvador had only one top performance in air pollution control category. Thailand performances in other categories were comparatively good and this have pushed Thailand to top rank. Thailand, Vietnam, Sri Lanka, Philippines and Senegal performed lower than all countries average in mitigating air pollution and this may be due to higher economic activities in these countries (Data World Bank, 2005). This suggests that they need to revise their strategy, policy and implementation in those categories.

\subsection{Case study: environmental performance of Sri Lanka}

- Within the group of countries:

- Sri Lanka's strategies and policies produced better results in the policy categories of ecosystem, climate change than other countries (Table 1). Leader in climate change category- top score among countries (Table 1).

- In water pollution and biodiversity results were somewhat aligned with the strategies and policies. Scores are above average than all countries category and their respective county's average scores.

- The environmental burden of diseases and Air pollution categories need more attention in strategies, policy implementation and evaluation processes. Scores are lower than category, country and all country average. The 
performance on air pollution is worse in all other countries except in Philippines and El Salvador. So that, the policy and implementation process need to be aligned for the best desired results.

- Among new policy sectors:

- Sri Lanka's worst sector performances are environmental burden of disease and air pollution. This needs more attention from policy makers.

- Climate change and ecosystem sector strategies and policies seem to be working but still need improvement in the implementation process. For example: Sri Lanka is well ahead of Montreal protocol implementation process.

- Water pollution and biodiversity sectors need more improvement in implementation process.

\subsection{Analysis of some selected indicators in a time series data}

Sri Lanka is doing better in climate change because the GHG emission is very much controlled by good policy implementation. Sri Lanka's performance on environmental burden on disease is very low due to higher respiratory illness as a result of air pollution. Air pollution includes $\mathrm{NO}_{\mathrm{x}}, \mathrm{SO}_{\mathrm{x}}$, particulate matter etc.

Green House Gas (GHG) emissions leads to global warming and climate changes. Air pollution caused by $\mathrm{CO}_{2}$ emission and Ozone Depleting Substances (ODS) leads to health hazards, livestock and poor production levels in other sectors such as agriculture, industry.

Sri Lanka is doing well in climate changes that is their GHG emission is lower and consumption of all ozone depleting substance is almost zero well ahead of Montreal protocol target implementation achievement. Therefore, the air pollution caused by the use of fossil fuel consumption is the main cause for the environmental burden of disease and air pollution category.

\section{$\mathrm{CO}_{2}$ emission metric ton per capita}

Over 18 years of span from 1990 to 2007, Thailand shows very higher increase in $\mathrm{CO}_{2}$ emission than any other country due to higher industrial activity and transport, while Vietnam (higher economic activity) and Salvador shows almost 1 and 0.6 metric ton increase of $\mathrm{CO}_{2}$ emission per capita respectively. Sri Lanka shows 0.4 metric ton increase in $\mathrm{CO}_{2}$ emission while Senegal and Philippines have done better in mitigating $\mathrm{CO}_{2}$ emission compared to other countries. In Sri Lanka, per capita $\mathrm{CO}_{2}$ emission increased from 0.21 Metric Tons to 0.61 MT from 1990 to 2007. Transport sector consume $80 \%$ of total fuel, while industrial sector and power generation activities consume $18 \%$ and $8 \%$ respectively (Institute of Policy Studies, 2010).

\section{Consumption of fossil fuel}

Fossil fuel energy consumption- percentage of total consumption For the 18 years from 1990 to 2007: has increased by $10 \%$ in El Salvador and in Senegal while Philippines and Thailand fossil fuel consumption have increased by $12 \%$ and $17 \%$ respectively. Sri Lanka's consumption has increased $21 \%$ and Vietnam's consumption was increased by $31 \%$. Due to high percentage increase in fossil fuel consumption the environmental health performance and air pollution is higher in Sri Lanka.

\subsection{Trend in fossil fuel consumption and CO2 emission and other indicators for Sri Lanka}

The use of fossil fuel is the major cause for $\mathrm{CO}_{2}$ emission in Sri Lanka (Institute of Policy Studies, 2010) and increasing trend (along with HDI and GDP per capita (2008 PPP US\$)) in emission. This increase in emission affect environmental burden of disease and air pollution.

\section{Sri Lanka's energy mix}

Sri Lanka's energy supply is mainly based on three primary resources such as biomass, petroleum and hydroelectricity. Primary energy contributions in 2004 to national energy supply were $48.2 \%$ from biomass, $44.2 \%$ from crude oil and petroleum products, and 7.6\% from hydroelectricity and other renewable sources (Ministry of power and Energy of Sri Lanka, 2011) Biomass provides cooking fuel and as heat source for small/ medium industries such as brick and tile industries. However the introduction of liquid petroleum gas (LPG) for domestic cooking decades ago has reduced use of firewood in the urban households. It also reduces the particulate matter pollution as well. The most common forms of biomass in Sri Lanka are, fuel wood, municipal waste, industrial waste and agricultural waste. The use of non- conventional energy resources such as solar, wind and geothermal resources in Sri Lanka is of a relatively smaller scale and therefore its contribution is presently of less significance in the macro energy picture.

\section{Conclusions and Recommendations}

HPI influences the new score very much when using simple average. The application of the Spearman correlation 
and the trend linear equation show that when considering the environmental sustainability EPI act as a better indicator than HPI and HDI.

Our new environmental performance category analysis shows that the growing demand on scarce resources and the pollution play an important role in environmental stress.

The pollution control, increasing fuel consumption trend are main factors that affects Sri Lanka's environmental performance. El Salvador's performance in air pollution control is higher than all other countries. Thailand, Vietnam, Sri Lanka, Philippines and Senegal are performing lower than all countries average in mitigating air pollution due to higher economic activities. These countries need to consider revising their strategy, policy and implementation process.

Difficulty in access to drinking water and access to sanitation in Senegal shows that they have to improve their facilities to improve their environmental performance (Refer proposed framework and calculations). Vietnam's lower biodiversity scores and higher economic growth suggests that they have to concentrate more on sustainable developmental activities. El Salvador's biodiversity score is lower due to lower land coverage by forest. Therefore, El Salvador may need to encourage sustainable forest growth and conserving it for the future use.

In order to reduce the consumption of fossil fuel, it would be better if Sri Lanka can consider developing other alternate energy mix and/ or introduce more environmental technological changes in industries and other sectors to sustain the development.

\section{Acknowledgement}

My thanks are due to Prof. Ivo Šlaus, Rudjer Bošković Institute, Zagreb, Croatia and Prof. Dr. Aleksander Zidanšek, International Postgraduate School, Ljubljana, Slovenia for their perspective and constructive guidance.

\section{References}

CIA fact files, (2005).

Data World Bank, (2005).

Environmental performance Index, Report. (2010). Yale Center for Environmental Law \& Policy Yale University http://envirocenter.research.yale.edu; Center for International Earth Science Information Network (CIESIN) Columbia University http://ciesin.columbia.edu In collaboration with World Economic Forum, Geneva, Switzerland; Joint Research Centre of the European Commission Ispra, Italy. [Online] Available: http://epi.yale.edu/file_columns/0000/0008/epi-2010.pdf (October, 2010).

Eurostat. (1997). Indicators of Sustainable Development, A pilot study following the methodology of the United Nations Commission on Sustainable Development, Statistical Office of the European Communities Luxembourg, ISBN 92-827-9827-5.

Herman Daly. (2009). New Economics Foundation (NEF) Happy Planet Index 2.0: Why good life don't have to cost the earth. [Online] Available: http://www.happyplanetindex.org/public-data/files/happy-planet-index-2-0.pdf (January, 2011).

Institute of Policy Studies. (2010). Millennium Development Goals Country Report 2008/2009, ISBN 978-955-8708-62-0, Sri Lanka.

Jonathan M. Harris, Neva R. Goodwin, Julie A. Nelson, P F Henshaw \& Cutler Cleveland. (2008). Encyclopaedia of Earth.

Ministry of power and Energy, Sri Lanka.http://power.lk/ (March, 2011).

Sikdar, S. K. (2007). 'Sustainable prospective and chemistry based technologies, Ind., Eng. Chem. Res., 46 (14), 4727-4733. http://dx.doi.org/10.1021/ie0700056

The New Economic Foundation (NEF), (2010), happy planet index 2.0. [Online] Available: http://www.happyplanetindex.org/public-data/files/happy-planet-index-2-0.pdf (November, 2010).

UNDP, Human Development Report. (2010). The Real Wealth of Nations: Pathways to Human Development. [Online] Available: http://hdr.undp.org/en/media/HDR_2010_EN_TechNotes_reprint.pdf .

United Nations. (2001). Indicators of Sustainable Development: Guidelines and Methodologies New York: United Nations (sales no. E.01.II.A.6). ISBN: 9211045061.

Jeffrey Wilson, Peter Tyedmersa \& Ronald Pelot. (2007). Contrasting and Comparing Sustainable Development Indicator metrics, Ecological Indicators. 7 (2), 299-314. http://dx.doi.org/10.1016/j.ecolind.2006.02.009 
World Bank, World Development Indicators. (2010). [Online] Available: http://data.worldbank.org/data-catalog/world-development-indicators/wdi-2010 (January, 2011).

Table 1. New environmental performance categories of selected countries

\begin{tabular}{|c|c|c|c|c|c|c|c|}
\hline $\begin{array}{c}\text { Categories/ } \\
\text { Country }\end{array}$ & $\begin{array}{c}\text { Environment } \\
\text { al burden of } \\
\text { disease } \\
(25 \%)\end{array}$ & $\begin{array}{c}\text { Climate } \\
\text { change } \\
(25 \%)\end{array}$ & $\begin{array}{c}\text { Ecosystem } \\
(12.5 \%)\end{array}$ & $\begin{array}{c}\text { Air } \\
\text { Pollution } \\
(16.5 \%)\end{array}$ & $\begin{array}{c}\text { Water } \\
\text { pollution } \\
(16.5 \%)\end{array}$ & $\begin{array}{c}\text { Biodiver } \\
\text { sity } \\
(4.5 \%)\end{array}$ & $\begin{array}{c}\text { Country } \\
\text { average }\end{array}$ \\
\hline El Salvador & 61.32 & 75.73 & 71.96 & 62.55 & 75.7 & 19.27 & 61.08 \\
\hline Senegal & 19.76 & 51.44 & 74.55 & 41.18 & 57.16 & 83.56 & 54.61 \\
\hline Sri Lanka & 41.41 & 79.71 & 73.36 & 38.41 & 76.76 & 79.17 & 64.8 \\
\hline Vietnam & 62.31 & 58.22 & 77.89 & 41.7 & 74.84 & 44.11 & 59.84 \\
\hline Thailand & 55.9 & 52.97 & 79.19 & 44.98 & 85.83 & 85.35 & 67.37 \\
\hline Philippines & 55.08 & 64.45 & 68.9 & 60.9 & 83 & 68.65 & 66.83 \\
\hline $\begin{array}{c}\text { Category } \\
\text { Average }\end{array}$ & 49.29 & 63.75 & 74.3 & 48.28 & 75.55 & 63.35 & 62.42 \\
\hline
\end{tabular}

Note: Data is obtained from EPI, 2010, modified and adapted according to proposed framework.

Italics $=$ All countries average

Table 2. New Aggregate Scores and Ranking with EPI Scores and Ranking

\begin{tabular}{|c|c|c|c|c|c|c|}
\hline Country & El Salvador & Senegal & Sri Lanka & Vietnam & Thailand & Philippines \\
\hline $\begin{array}{c}\text { Author's New } \\
\text { Aggregate } \\
\text { Score Rank }\end{array}$ & $\begin{array}{c}(61.08) \\
4\end{array}$ & $\begin{array}{c}(54.61) \\
6\end{array}$ & $\begin{array}{c}(64.8) \\
3\end{array}$ & $\begin{array}{c}(59.84) \\
5\end{array}$ & $\begin{array}{c}(67.37) \\
1\end{array}$ & $\begin{array}{c}(66.83) \\
2\end{array}$ \\
\hline $\begin{array}{l}\text { EPI Rank } \\
\text { Score }\end{array}$ & $1 \quad(69.1)$ & $6 \quad(42.3)$ & $\begin{array}{c}3 \\
(63.7)\end{array}$ & $(59.0)$ & $(62.2)$ & $(65.7)$ \\
\hline
\end{tabular}




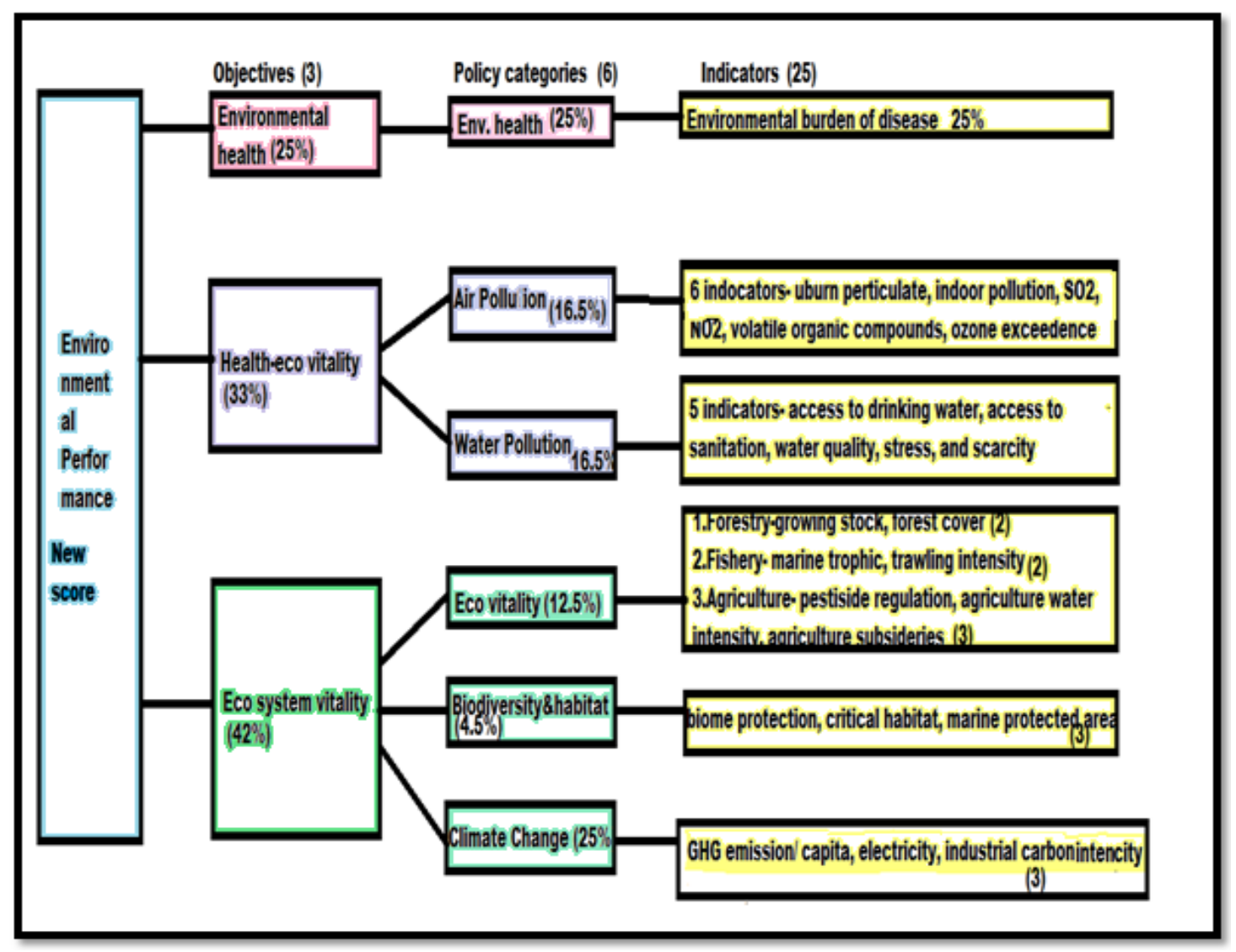

Figure 1. Proposed Framework for New Score

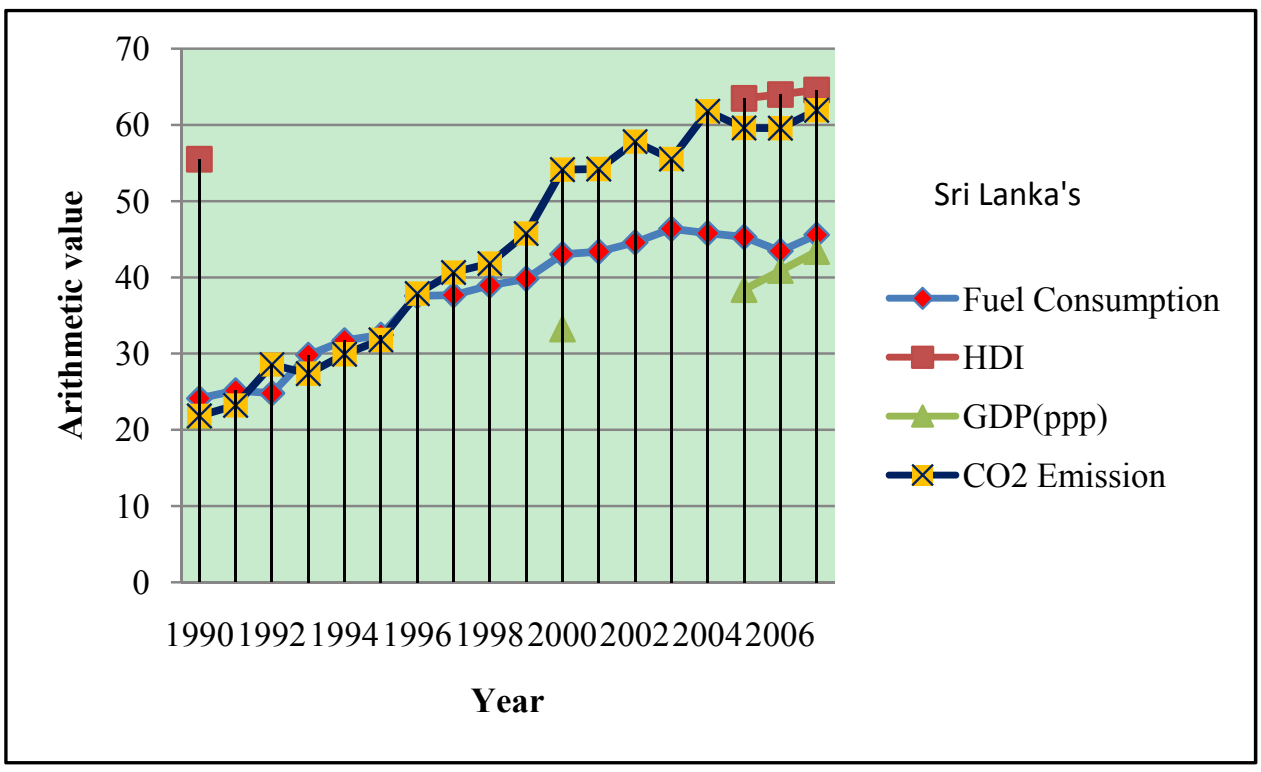

Figure 2. Consumption of Fossil Fuel and other indicators for Sri Lanka 